\title{
A STUDY TO ASSESS EFFECTIVENESS OF STRUCTURED TEACHING PROGRAMME ON KNOWLEDGE OF DIABETIC PATIENTS REGARDING DIABETES COMPLICATIONS AND PREVENTION AT SELECTED HOSPITAL, TUMKUR.
}

*Prof. K. Ramu \&**Dr. N.V. Muninarayanappa

\section{INTRODUCTION:}

According to recent World Health Organization report, India has the largest number of diabetic patients in the world. The rising trend in the prevalence of type 2 diabetes has also been reported in a series of epidemiological studies.

It has been estimated that the global burden of type 2 diabetes for 2010 would be 285 million people which is projected to increase to 438 million in 2030, a 65\% increase. Similarly, for India this increase estimated to be $58 \%$ from 51 million people in 2010 to 87 million in 2030 (Snehalatha \& Ramachandran 2009). The impacts of type 2 diabetes are considerable as a lifelong disease, it increases morbidity \& mortality, decrease the quality of life. (Hoskote \& Joshi 2008). At the same time the disease \& its complications cause a heavy economic burden for diabetic patients themselves, their families \& society.

The burden of diabetes is to a large extent the consequence of macrovascular (Coronary artery disease, peripheral vascular disease \& atherosclerosis) and microvascular (like retinopathy, neuropathy \& nephropathy) complications of diabetes. The complications of diabetes mellitus are major causes of hospital admissions. Asian patients had more evidence of macro \& micro vascular complications at diagnosis of diabetes. Several studies showed that the prevalence of microvascular \& macro vascular complications were more in Asians when compared to Europeans. Life style modifications such as weight control, increase physical exercise \& smoking cessation are also potentiality beneficial in preventing diabetes mellitus.

A research study by Harney etal suggested that some common risk factors like greater duration of diabetes, hypertension, poor metabolic control, smoking, obesity \& hyperlipidemia were most prone to develop diabetic complications. Majority of subjects did not have their diabetes controlled. Therefore strategies to enhance \& promote self efficacy \& self management behaviors for patients are essential components of diabetes education programs. Further more behavior counseling \& skill building interventions are critical for patients to become confident \& be able to manage their diabetes.

In a research study conducted at B.M. Patil Medical Hospital, Bijapur, Karnataka, The researchers revealed that patient's knowledge about diabetes \& its complications is poor. The study recommended that awareness \& education programmes are required to empower diabetic patients $\&$ also to increase their quality of life.

\section{NEED FOR STUDY :}

The incidence of diabetes is rising throughout the world. Adequate knowledge of diabetes is a key components of diabetic care. Studies has show that increasing patients knowledge regarding diabetes \& its

\footnotetext{
*Principal, Shridevi Institute of Nursing, Tumkur, Karnataka \& **Principal \&DeanSchool of Nursing Science \& Research, Sharada University, Greater Noida Uttar Pradesh.
} 
complications has significant benefits with regard to patients compliance to treatment and to decreasing complications associated disease. Many patients in Govt. District hospital, Tumkur are not aware of diabetes \& its effects on health.

\section{STATEMENT OF THE PROBLEM:}

A study to assess effectiveness of structured teaching programme on knowledge of diabetic patients regarding diabetes complications and prevention at selected hospital, Tumkur.

\section{OBJECTIVES:}

1. To determine the level of knowledge of diabetic patients regarding diabetes complications \& prevention.

2. To administer structured teaching programme on diabetes complications \& prevention among diabetic patients.

3. To determine the effectiveness of structured teaching programme by comparing pre \& post test scores.

4. To determine the association between pre-test knowledge score with selected demographic variables.

\section{RESEARCH HYPOTHESES:}

$\mathbf{H}_{1}$ : There is a significant difference between pre and post knowledge scores of diabetic patients regarding diabetes complications \& prevention.

$\mathbf{H}_{\mathbf{2}}$ :Thereis a significant association between pretest knowledge scores with selected demographic variables.

\section{RESEARCH METHODOLOGY:}

Research Approach: An evaluative approach to assess the effectiveness of STP among diabetic patients in order to accomplish the objectives of study.

Research Design:One group pretest posttest experimental design.

Setting of the study: The study was conducted at Govt. District Hospital, inpatient \& outpatient wards, Tumkur.

Population: Diabetic patients who were admitted to Govt. District Hospital, Tumkur.

Sample \& Sample size:

The sample selected for this study comprised of diabetic patients who were attending OPD \&admitted inpatient wards.

Sample Size : 50 Diabetic Patients.

Sample Technique: A Non-probability purposive sampling technique was used.

Criteria for sample selection inclusion criteria:

1. Type I\& Type II diabetic patients who were willing to participate in the study.

2. Type I\& Type II diabetic patients who were attending OPD \&admitted Inpatient ward.

3. Those who can understand kannada \& English.

\section{Exclusion criteria:}

1. Diabetic patients who were not willing to participate in the study.

\section{Data Collection Technique:}

A structured interview schedule was used for assessing the knowledge of diabetic patients regarding diabetes complications \& prevention.

Description of the tool: The structured questionnaire consisted of two (2) sections.

1.Section I: It consists of two parts. 
a. Part I : It consisted of 10 items on demographic data such age, gender, education status, occupation, family income, religion, residential area, food habits, personal habits, duration of diabetes.

b. Part II: It consisted of 5 items on clinical proforma of diabetes patients.

2. Section II: It consists of 40 Questionnaires related to knowledge on diabetes mellitus and diabetes complication and its prevention.

\section{PROCEDURE OF DATA COLLECTION:}

Prior permission was obtained from hospital authority and the purpose of the study was explained to subjects \& informed consent was taken before starting the study.

\section{Results:}

Age: It is observed that $20 \%$ of diabetic patients were in the age group of 40-49 years, $40 \%$ were in the age group of 50-59, $20 \%$ were in the age group of $60-69 \& 20 \%$ were in the age group of 70-79 years.

Gender: It is observed that $72 \%$ (36) were males \& $28 \%$ (14) were female diabetic patients.

Education Status: Majority of diabetic patients were illiterate $(60 \%), 30 \%$ had primary education \& $6 \%$ had completed secondary level of education, $4 \%$ had completed graduation.

Occupation: It is observed that $20 \%$ diabetic patients belongs to Govt, $30 \%$ belongs to private, $30 \%$ belongs to business \& $20 \%$ of belongs to no job/coolie.

ReligionItis observedthat $46 \%$ diabetic patients are Hindus, 40\%diabetic patientsare Muslims, $10 \%$ diabetic patients are Christians and $4 \%$ diabetic patients belong of other casts.
Income: It is observed that $20 \%$ of diabetic patients belongs to below $2000,40 \%$ belongs to 2000- 4000, 20\% belongs $4000-6000 \& 20 \%$ belongs to above 6000 .

Residential Area: It is observed that $30 \%$ of diabetic patients belongs to urban area \& $70 \%$ belongs to rural area.

Food Habits: It is observed that majority of the diabetic patients $(72 \%)$ are non-vegetarian \& $28 \%$ belongs to vegetarian.

Personal Habits: It is observed that $30 \%$ of diabetic patients had habit of smoking, $30 \%$ had habit of alcohol, $20 \%$ had habits of tobacco chewing \& $20 \%$ had no habits.

Duration of illness: it is observed that $6 \%$ diabetic patients belongs to below 2 years of illness, $30 \%$ of diabetic patients are having diabetes from 02 to 5 years, $50 \%$ belongs to $6-10$ years $14 \%$ belongs to above 10 years.

\section{Duration of illness}

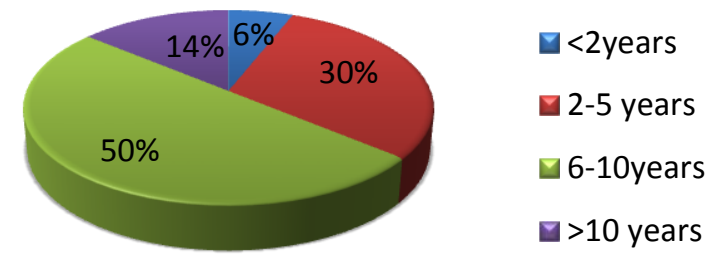

Fig:2- Distributionofdiabetic patients according to duration of illness Major Findings:

The Data reveals that $40 \%$ of diabetic subjects belong to age group of 50-59 years. $72 \%$ were males and $60 \%$ were illiterates. As per occupation is concerned $30 \%$ of subjects had to private job, $30 \%$ were doing business. 
Regarding income of the subjects majority $40 \%$ belong to income group of Rs 2000-4000 per month. Regarding religion $46 \%$ were Hindus. $70 \%$ were residing at rural areas and $72 \%$ were non vegetarians.

Related to personal habits of diabetic subjects, $30 \%$ were having habit of smoking and $30 \%$ were having habit of consuming alcohol. Regarding duration of illness majority (60\%) subjects were suffering from diabetes since 6-10 years

Discussion: The present study showed that Pretest knowledge among diabetic patients regarding diabetes complications \& prevention was inadequate in $80 \%$ of subjects and moderate in 20\% subjects. Posttest knowledge score regarding diabetes complications \& prevention was moderate in $74 \%$ and adequate in $20 \%$ of subjects.

This showed that gain in knowledge among diabetic patients regarding complications \& prevention of diabetes was moderate after STP. The overall mean is 13.16; standard deviation is $2.41 \&$ mean percentage is 32.9 in pretest. whereas in post test, overall mean is 28.48 , SD is 1.4 and mean percentage is 71.2.

Results of socio demographic characteristics \& knowledge of diabetic patients regarding diabetes complication \& prevention shows that, educational status, residential area, food habits, personal habits are significant. The other variables such as age, gender, occupations, monthly income, religion, duration of illness are not significant. The administration of STP can improve knowledge of diabetic patients regarding diabetes complications \& prevention
Conclusion: Theresults of the study concluded that many diabetic patients have poor knowledge regarding their diabetes complications \& prevention \& more concerned efforts would need to be made by nurses to help the diabetic patients to find out the causes of hypertension, poor frequently monitor this risk factors \& give proper treatment so that the nurse can prevent the diabetic complications.

\section{REFERENCE:}

World Health Organization study group: Prevalence of small \& large vessels disease in diabetic patients. World health organization multinational study of vascular disease in diabetes. Diabetologia.1985:28:615-40

Ramachandran. A., Snehalatha. C., Satyavani. K., Latha. E., prevalence of vascular complications and their risk factors in type 2 diabetes. Journal of Assoc physicians India 1997:47:1152-6

Alkh Waldeh OA, A I- Hassan, self efficacy, self management\& glycemic control in adults with type 2 diabetes, journal of diabetes $\&$ its complications. 2007,26, 10-16.

Vijaya Sorganvi, S.S. Devarmani, M. Angadi, RekhaUdgiri, (2013) Knowledge \& its complications of diabetes among the known diabetic patients- A hospital based study, International Journal of Clinical Research $5(22)$ 